\title{
Hipertermia e Drogas no Brasil - Ceatox
}

\section{Drug induced hyperthemia in Brasil - Ceatox}

\author{
Anthony Wong \\ CEATOX do Hospital das Clínicas da Faculdade de Medicina, Universidade de São Paulo - USP.
}

\section{Hipertermia Maligna - Legislação no Estado de São Paulo}

\section{Brazilian laws on MH in Brazil. São Paulo City Office}

\section{Vereador Paulo Teixeira}

O movimento que levou à promulgação da lei $\mathbf{n}^{\mathbf{0}} \mathbf{1 0 . 7 8 1}$, de 9 de março de 2001, se originou na Sempre Viva e contou com o apoio da Associação Paulista de Medicina, através do Dr. José Luiz Gomes do Amaral, e dos familiares de portadores.

Com eles, aprendemos que a Hipertermia Maligna é uma síndrome, ligada à uma herança genética, sem sinais clínicos aparentes, desencadeada por anestésicos gerais halogenados, bem como por relaxantes musculares despolarizantes. As dificuldades para a detecção da suscetibilidade nos levou a crer que a conduta mais adequada seria a preventiva. Percebemos a urgência em obrigar o Poder Público a se preparar para o diagnóstico, tratamento e registro das ocorrências desta síndrome no Estado.

O desconhecimento da síndrome, a falta de diagnóstico correto e o consequente tratamento inadequado leva pessoas à morte, e diante deste quadro elaboramos o projeto de lei 867/99, que tinha como objetivo instituir uma política de prevenção, diagnóstico e tratamento da hipertermia maligna.

Nosso fundamento foi a determinação constitucional quanto à assistência universal e integral à saúde, de competência do Estado, bem como a Lei 8.080/90 e a lei estadual 10.083, de 23 de setembro de 1998 (Código Sanitário). 
O Governador do Estado vetou parcialmente a lei, retirando as disposições constantes do inciso II do artigo $2^{\circ}$ e as do artigo $3^{\circ}$ e $4^{\circ}$ - respectivamente, a garantia de que todos os hospitais públicos e particulares, bem como as demais empresas que prestem assistência médico-hospitalar, no Estado, diretamente ou por intermediação, possuam medicamentos apropriados para o combate à doença em questão, especialmente, o Dantroleno Sódico; a obrigação de tais estabelecimentos terem, em seus estoques, os mencionados medicamentos; e a sanção caso não cumpram a lei.

$\mathrm{O}$ argumento dado pelo Executivo foi: "essa imposição, importando em incalculável dispêndio, dada a inexistência de estatísticas nacionais de morbi-mortalidade, relativas à Hipertermia Maligna - HM, que permitam adequado levantamento de dados para que os estabelecimentos de assistência à saúde possam fazer previsão para estoque inicial e de manutenção desses medicamentos, revela-se impraticável, daí decorrendo a impossibilidade da subsistência das disposições ora impugnadas, vetando-se, em decorrência, o artigo $4^{\circ}$, por desnecessárias as sanções aí previstas, ante a inocorrência de infrações, dado o não prevalecimento da norma inscrita no artigo $3^{\circ}$ do texto. Afinal, (..) o estabelecimento de medidas de controle da síndrome dependem da constituição de Comissão Técnica para Estudo e Prevenção da Hipertermia Maligna, composta por membros de diversas instâncias da Pasta, das Universidades e entidades representativas das categorias médicas envolvidas, o qual deverá, dentre outras atribuições, realizar estudos epidemiológicos sobre esse agravo à saúde, conforme determina o artigo $7^{\circ}$, inciso VII, do Código Nacional de Saúde (Lei federal $\mathrm{n}^{\mathbf{o}}$ 8080/90), tendo em vista as diretrizes do artigo 198 da Constituição da República.”

Este veto foi analisado pela Assembléia Legislativa, que decidiu derrubá-lo em parte, resgatando o artigo $2^{\circ}$, inciso II do projeto original e o artigo $4^{\circ}$ (mas sem a multa) e mantendo os vetos aos artigos $3^{\circ}$ e $5^{\circ}$. A lei ficou assim:

\section{Lei $\mathrm{n}^{\circ}$ 10.781, de 9 de março de 2001}

Dispõe sobre a Política Estadual de Prevenção, Diagnóstico e Tratamento da Hipertermia Maligna - HM no Estado de São Paulo, e dá providências correlatas.

\section{O GOVERNADOR DO ESTADO DE SÃO PAULO:}

Faço saber que a Assembléia Legislativa decreta e eu promulgo a seguinte lei: 
Art. $1^{\text {o }}$ Fica instituída no Estado a Política para Prevenção, Diagnóstico e Tratamento da Hipertermia Maligna - HM, que será desenvolvida nos termos desta lei pelo Poder Executivo em parceria com a sociedade civil.

Art. $2^{\circ}$ A Política para Prevenção, Diagnóstico e Tratamento da Hipertermia Maligna HM tem como objetivos:

I - prevenir, diagnosticar, tratar e orientar adequadamente os pacientes suscetíveis de hipertermia maligna e seus familiares;

II - garantir que todos os hospitais públicos e particulares, as empresas de medicina de grupo, cooperativas de trabalho médico, ou outras que atuem sob a forma de prestação direta ou intermediação dos serviços médico-hospitalares e operem no Estado, possuam medicamentos apropriados para o combate da doença, em especial o Dantroleno Sódico;

III - erradicar o número de mortes decorrentes desta síndrome no Estado;

IV - produzir materiais de divulgação para os profissionais do setor da saúde no Estado contendo as principais informações sobre a hipertermia maligna e as formas de se evitar os seus efeitos mortais nos pacientes;

V - realizar palestras informativas sobre a hipertermia maligna para médicos e paramédicos em hospitais de referências no Estado;

VI - implantar um sistema de coleta de dados sobre os portadores da síndrome visando:

a) manter um Cadastro Estadual com informações sobre a incidência da doença na população paulista e o número de mortes dela decorrentes;

b) obter elementos informadores sobre a população atingida pela moléstia;

c) contribuir para o aprimoramento das pesquisas científicas sobre a hipertermia maligna;

d) firmar convênios com os serviços funerários existentes no Estado para que informem toda vez que houver vítimas da síndrome.

Art. $3^{\circ}$ Vetado.

Art. $4^{\circ}$ A inobservância dos preceitos desta lei sujeitará os infratores a (vetado) sanções penais e civis cabíveis em espécie.

Art. $5^{\circ}$ O Poder Executivo regulamentará esta lei no prazo de 30 (trinta) dias, a contar da data de sua publicação.

Art. $6^{\circ}$ As despesas decorrentes da execução desta lei correrão à conta de dotações orçamentárias próprias, suplementadas se necessário. 
Art. $7^{\circ}$ Esta lei entra em vigor na data de sua publicação, revogadas as disposições em contrário.

Portanto, a diferença central entre a lei e o projeto original está no artigo $3^{\circ}$, que estabelecia que "os Hospitais e Postos de Saúde, públicos e particulares, as empresas de Medicina de Grupo, cooperativas de trabalho médico, ou outras que atuem sob a forma de prestação direta ou intermediação dos serviços médico-hospitalares e operem no Estado de São Paulo, estão obrigadas a dispor, em seus estoques, dos medicamentos necessários para o tratamento da Hipertermia Maligna".

Esta lei serviu como modelo para a apresentção de projetos em outros locais e em nível federal.

Cerca de um ano após a sanção, foi publicado o Decreto 46.601, de 12 de março de 2002, que regulamentou a lei, estabelecendo que o Programa Estadual de Prevenção, Diagnóstico e Tratamento da Hipertermia Maligna (PROPREV - HM) insere-se na Política de Prevenção, Diagnóstico e Tratamento da Hipertermia Maligna (HM) do Estado de São Paulo, sob a Coordenação da Secretaria da Saúde, e abrange, além da Administração Direta, as Autarquias, as Fundações instituídas ou mantidas pelo Poder Público, bem como as demais instituições direta ou indiretamente vinculadas ao Estado, ou com ele conveniadas ou contratadas para execução de ações e atividades de saúde no âmbito do Sistema Único de Saúde - SUS/SP.

Caberia à Secretaria da Saúde constituir Grupo Técnico Permanente com as seguintes atribuições: instituir, organizar e inserir informações/dados no Cadastro Estadual de Informações sobre a incidência, prevalência e óbitos decorrentes da HM; elaborar no prazo de 120 (cento e vinte) dias, Norma Técnica visando disciplinar os aspectos múltiplos referentes à prevenção, diagnóstico e tratamento da HM e, no mesmo prazo, protocolo específico para a investigação clínico-epidemiológico dos casos de HM; promover levantamentos, estudos epidemiológicos/estatísticos e pesquisas sistemáticas na literatura científica e por meio de rastreamento na população, com o objetivo de obter informes a respeito da incidência e prevalência de HM em nosso meio; e divulgar, periodicamente, informações atualizadas sobre a Síndrome da HM e formas para evitar seus efeitos, visando subsidiar as ações de profissionais e entidades ligadas à saúde.

O decreto estabelece ainda que as entidades de assistência à saúde do Estado, integrantes ou não do Sistema Único de Saúde - SUS/SP, que realizam procedimentos 
médico-cirúrgicos deverão notificar, ao Centro de Vigilância Sanitária da Secretaria da Saúde, imediatamente após a adoção das condutas terapêuticas indicadas, o diagnóstico de quadros clínicos de HM, o mesmo se aplicando aos Serviços de Verificação de Óbito - SVO e Instituto Médico Legal - IML, relativamente aos casos suspeitos de HM verificados nos respectivos âmbitos de atuação.

Por fim, as entidades de assistência à saúde, integradas ou não ao SUS/SP que realizam procedimentos com o uso de medicamentos que possam desencadear Hipertermia Maligna deverão garantir o tratamento específico imediato dos pacientes que vierem a apresentar quadro clínico de HM, responsabilizando-se civil e criminalmente pela eventual omissão.

Perguntamos: esta lei tem sido aplicada? Como anda a prevenção, o diagnóstico e o tratamento da Hipertermia Maligna no Estado de São Paulo? Os médicos, profissionais da saúde, familiares e portadores aqui presentes podem, melhor do que ninguém, nos dar esta resposta. 